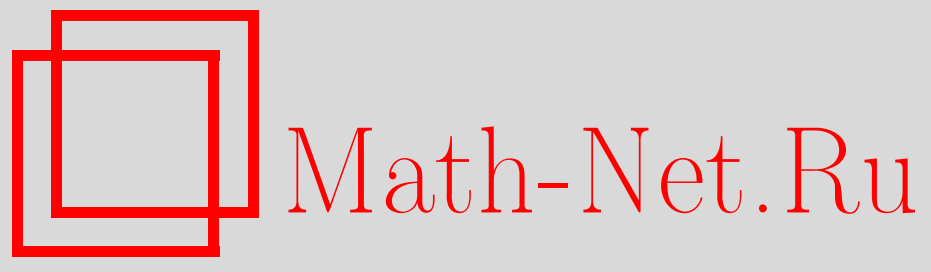

B. Roos, Kerstan's method in the multivariate poisson approximation: an expansion in the exponent, Teopus вероятн. и ее примен., 2002, том 47, выпуск 2, 397402

DOI: https://doi.org/10.4213/tvp3672

Использование Общероссийского математического портала MathNet.Ru подразумевает, что вы прочитали и согласны с пользовательским соглашением

http://www . mathnet.ru/rus/agreement

Параметры загрузки:

IP: 3.89 .197 .203

26 апреля 2023 г., 18:05:22

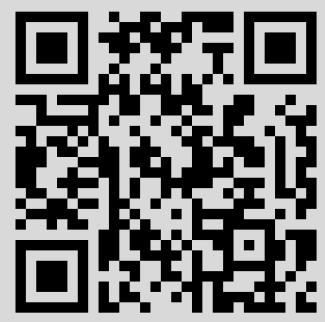


6. Diaconis P., Freedman D. Iterated random functions. -- SIAM Rev., 1999, v. 41, № 1, p. $45-76$.

7. Dudley R. M. Probabilities and metrics. Convergence of laws on metric spaces, with a view to statistical testing. Aarhus: Matematisk Institut, Aarhus Universitet, 1976. (Lecture Notes Ser., № 45).

8. E W., Khanin K., Mazel A., Sinai Ya. Invariant measures for Burgers equation with stochastic forcing. - Ann. of Math. (2), 2000, v. 151, № 3, p. 877-960.

9. Kifer Yu. Ergodic Theory of Random Transformations. Boston: Birkhäuser, 1986, $210 \mathrm{p}$.

10. Letac G. A contraction principle for certain Markov chains and its applications. Contempt. Math., 1986, v. 50, p. 263-273.

11. Mattingly J.C. Ergodicity of 2D Navier-Stokes equations with random forcing and large viscosity. - Comm. Math. Phys., 1999, v. 206, № 2, p. 273-288.

Поступила в редакцию 22.XI.2001

(C) 2002 г.

ROOS B.*

\section{KERSTAN'S METHOD IN THE MULTIVARIATE POISSON APPROXIMATION: AN EXPANSION IN THE EXPONENT}

Обобщенное полиномиальное распределение аппроксимируется конечными мерами со знаком, возникающими в разложении пуассоновского типа в экспоненте.

В одномерном случае это разложение впервые было использовано в [9] и [11]. Мы применяем метод Керстена и приводим оценку расстояния по вариации с указанием явного вида констант.

Ключевые слова и фразы: разложение в экспоненте, обобщенное полиномиальное распределение, метод Керстена, многомерная пуассоновская аппроксимация, расстояние по вариации.

1. Introduction and results. Let $S_{n}$ be the sum of independent Bernoulli random vectors $X_{1}, \ldots, X_{n}$ in $\mathbf{R}^{k}(k, n \in \mathbf{N}=\{1,2, \ldots\})$ with probabilities

$$
\mathbf{P}\left\{X_{j}=e_{r}\right\}=p_{j, r} \in[0,1], \quad \mathbf{P}\left\{X_{j}=0\right\}=1-p_{j} \in[0,1]
$$

for $j \in\{1, \ldots, n\}$ and $r \in\{1, \ldots, k\}$, where $p_{j}=\sum_{r=1}^{k} p_{j, r}$ and $e_{r}$ denotes the vector in $\mathbf{R}^{k}$ with entry 1 at position $r$ and 0 otherwise. We assume that $\lambda_{r}=\sum_{j=1}^{n} p_{j, r}>0$ for all $r$.

In this paper, we are concerned with the approximation of the distribution $P^{S_{n}}$ of $S_{n}$ by the finite signed measures $\mathscr{P}_{s}(s \in \mathbf{N})$ concentrated on $\mathbf{Z}_{+}^{k}$ with the generating function

$$
\Psi_{\mathscr{P}_{s}}(z)=\sum_{l \in \mathbf{Z}_{+}^{k}} \mathscr{P}_{s}(\{l\}) z^{l}=\exp \left(\sum_{m=1}^{s} G_{m}(z)\right) \quad\left(z=\left(z_{1}, \ldots, z_{k}\right) \in \mathbf{C}^{k}\right),
$$

where $\mathbf{Z}_{+}=\{0,1,2, \ldots\}, z^{l}=z_{1}^{l_{1}} \cdots z_{k}^{l_{k}}$ for $l=\left(l_{1}, \ldots, l_{k}\right) \in \mathbf{Z}_{+}^{k}$, and, for $m \in\{1, \ldots, s\}$ and $z \in \mathbf{C}^{k}$,

$$
G_{m}(z)=\frac{(-1)^{m+1}}{m} \sum_{j=1}^{n}\left[H_{j}(z)\right]^{m}, \quad H_{j}(z)=\sum_{r=1}^{k} p_{j, r}\left(z_{r}-1\right) \quad(j \in\{1, \ldots, n\}) .
$$

* Schwerpunkt Math. Statistik und Stoch. Prozesse, Fachbereich Mathematik, Universität Hamburg, Bundesstraße 55, D-20146 Hamburg, Germany; e-mail: roos@math.uni-hamburg.de 
An approximation by $\mathscr{P}_{s}$ may be useful, since, for the probability generating function $\Psi_{S_{n}}(z)$ of $P^{S_{n}}$, the following relations hold:

$$
\Psi_{S_{n}}(z)=\sum_{l \in \mathbf{Z}_{+}^{k}} \mathbf{P}\left\{S_{n}=l\right\} z^{l}=\prod_{j=1}^{n}\left(1+H_{j}(z)\right)=\exp \left(\sum_{m=1}^{\infty} G_{m}(z)\right)
$$

if $z \in \mathbf{C}^{k}$ with $\max _{1 \leqslant r \leqslant k}\left|z_{r}-1\right|<1$. Note that $\mathscr{P}_{s}\left(\mathbf{Z}_{+}^{k}\right)=\Psi_{\mathscr{P}_{s}}(1)=1$.

In the univariate case $k=1$, the first results concerning the above expansion are due to Kornya [9] and Presman [11]. Therefore we call this expansion a Kornya-Presman expansion. It should be mentioned that Presman considered the binomial case with $s=2$. Further results came from Kruopis [10] and Barbour and Xia [2] (for $k=1$ and $s=2$ ), and Hipp [7] and Čekanavičius [3] (for $k=1$ and arbitrary $s$ ). The multivariate Poisson case with $s=1$ and arbitrary $k$ was treated, for example, by Barbour [1], Deheuvels and Pfeifer [5], and Roos [13], [14]. For this case, see also the references in [13]. The method of this paper is originally due to Kerstan [8], who considered the case $k=s=1$. Refinements of this method came from Daley and Vere-Jones [4, p. 297-299], Witte [15], and Roos [12, Chapter 8], [14].

In what follows, further notation is needed. Let

$$
\begin{gathered}
s \in \mathbf{N}, \quad p_{0}=\max _{1 \leqslant j \leqslant n} p_{j}, \quad \widetilde{p}_{0}=\sum_{r=1}^{k} \max _{1 \leqslant j \leqslant n} p_{j, r}, \\
\beta_{s}(x)=\sum_{j=1}^{n}\left[\min \left\{x \sum_{r=1}^{k} \frac{p_{j, r}^{2}}{\lambda_{r}}, p_{j}^{2}\right\}\right]^{(s+1) / 2}(x \in[0, \infty)) .
\end{gathered}
$$

Observe that

$$
p_{0} \leqslant \widetilde{p}_{0}, \quad \beta_{s}(x) \leqslant\left[\beta_{1}(x)\right]^{(s+1) / 2} \leqslant\left(x \widetilde{p}_{0}\right)^{(s+1) / 2} .
$$

For $y \in \mathbf{C}$, let

$$
U_{s}(y)=\exp \left(\sum_{m=1}^{s} \frac{y^{m}}{m}\right), \quad V_{s}(y)=\left[1-(1-y) U_{s}(y)\right] \frac{s+1}{y^{s+1}} .
$$

Note that $(1-y) U_{s}(y)$ is the prime function used by Weierstrass (see [6, p. 227]). For $x \in \mathbf{R}$, let $\lceil x\rceil$ denote the smallest integer $\geqslant x$. Let $A, B \in[0,1]$ with $A+B=1$. However, to get reasonable inequalities, it must often be assumed that $A, B \in(0,1)$. In this paper, we frequently deal with power series of the type $W(z)=\sum_{l \in \mathbf{Z}_{+}^{k}} w_{l} z^{l}\left(w_{l} \in \mathbf{R}\right)$, which are absolutely convergent for all $z \in \mathbf{C}^{k}$. In particular, the order of summation may be chosen arbitrarily. We write $\|W(z)\|=\sum_{l \in \mathbf{Z}_{+}^{k}}\left|w_{l}\right|$ and use the easy fact that $\left\|W_{1}(z) W_{2}(z)\right\| \leqslant$ $\left\|W_{1}(z)\right\|\left\|W_{2}(z)\right\|$ for two power series $W_{1}(z)$ and $W_{2}(z)$.

In the following theorem, we give an upper bound for the total variation distance $d_{s}=2^{-1}\left\|\Psi_{S_{n}}(z)-\Psi_{\mathscr{P}_{s}}(z)\right\|$ between $P^{S_{n}}$ and $\mathscr{P}_{s}$.

Theorem 1. Let

$$
\begin{aligned}
c_{1}(s) & = \begin{cases}(s+1) 2^{-5 / 2}, \\
(s+1) 2^{1 /[2(s+1)]-5 / 2}, & \text { for odd } s\end{cases} \\
c_{2}\left(s, p_{0}\right) & =\frac{e 2^{s}\lceil s / 2-1\rceil !}{\sqrt{2 \pi}(s+1)} V_{s}\left(2 p_{0}\right), \\
c_{3}\left(s, p_{0}\right) & =\frac{e 2^{s+1}}{s+1} V_{s}\left(2 p_{0}\right), \quad c_{4}\left(s, p_{0}\right)=4 e \sum_{m=2}^{s} \frac{\left(2 p_{0}\right)^{m-2}}{m}
\end{aligned}
$$

If $c_{3}\left(s, p_{0}\right) p_{0}^{s-1} \beta_{1}\left(2^{-3 / 2} B^{-1}\right)<1$ and $c_{4}\left(s, p_{0}\right) \beta_{1}\left(2^{-3 / 2} A^{-1}\right)<1$, then

$$
d_{s} \leqslant \frac{c_{2}\left(s, p_{0}\right) \beta_{s}\left(c_{1}(s) B^{-1}\right)}{\left[1-c_{3}\left(s, p_{0}\right) p_{0}^{s-1} \beta_{1}\left(2^{-3 / 2} B^{-1}\right)\right]^{[s / 2\rceil}\left[1-c_{4}\left(s, p_{0}\right) \beta_{1}\left(2^{-3 / 2} A^{-1}\right)\right]} .
$$


R e m a rks. (a) Considering the properties of the Weierstrass prime function (see [6, p. 227]), we obtain $V_{s}(y)=\sum_{i=0}^{\infty} v_{s, i} y^{i}(y \in \mathbf{C})$, where $v_{s, 0}=1$ and $v_{s, i} \geqslant 0$ for all $i \geqslant 1$. Therefore $V_{s}(x)$ is increasing in $x \in[0, \infty)$. Further, for these $x$, we have $V_{s}(x) \leqslant U_{s}(x)$, since this is equivalent to

$$
1 \leqslant U_{s}(x)\left(1-x+\frac{x^{s+1}}{s+1}\right)
$$

which follows from the observation that the term on the right-hand side is increasing in $x \in[0, \infty)$. Note also that $U_{s}(x) \leqslant(1-x)^{-1}$ for $x \in[0,1)$. The inequalities given here can be used to obtain upper bounds for the constants $c_{2}\left(s, p_{0}\right)$ and $c_{3}\left(s, p_{0}\right)$.

(b) In the case $k=1$ and $s=2$, inequality (2) substantially coincides, up to constants, with the inequalities given by Presman [11, Assertion 1(a)] and Kruopis [10, Theorem 3], respectively. If $k$ is arbitrary and $s=1$, we can choose $A=0$ and $B=1$, since $c_{4}\left(1, p_{0}\right)=0$; in this case, (2) is comparable with inequality (5) in [14].

(c) There exist positive constants $c_{5}$ and $c_{6}(s)$, such that, if $\widetilde{p}_{0} \leqslant c_{5}$, the inequality $d_{s} \leqslant c_{6}(s) \beta_{s}(1)$ is valid for all $s$. Note that $c_{5}$ does not depend on $s$. Indeed for $s=1$, such an inequality with $c_{6}(1)=8.8$ was proved in $[14$, formula (6)] without any restrictions on $\widetilde{p}_{0}$. Further, letting $A=0.745$ and using (1), (2), and Remark (a), it is easily shown that one can choose $c_{5}=\frac{1}{4}$. Here it suffices to verify that an $\varepsilon \in(0,1)$ exists such that, for all $s \in\{2,3, \ldots\}$ and $\widetilde{p}_{0} \leqslant \frac{1}{4}$,

$$
c_{3}\left(s, p_{0}\right) p_{0}^{s-1} \beta_{1}\left(2^{-3 / 2} B^{-1}\right)<1-\varepsilon \quad \text { and } \quad c_{4}\left(s, p_{0}\right) \beta_{1}\left(2^{-3 / 2} A^{-1}\right)<1-\varepsilon .
$$

The special value for $A$ was taken to obtain a large $c_{5}$. It should be mentioned that, in the general case $s \in \mathrm{N}$, it is not clear, whether the above condition $\widetilde{p}_{0} \leqslant c_{5}$ can be dropped.

For a successful approximation, we have to compute the values of $\mathscr{P}_{s}$. In the following proposition, we give a recursive formula for the counting density of $\mathscr{P}_{s}$. Observe that $\mathscr{P}_{s}(\{0\})=\Psi_{\mathscr{P}_{s}}(0)$. For $l=\left(l_{1}, \ldots, l_{k}\right) \in \mathbf{Z}_{+}^{k}$, we use the standard multi-index notation $|l|=l_{1}+\cdots+l_{k}$ and $l !=l_{1} ! \cdots l_{k}$ !. Further, if additionally $t \in \mathbf{Z}_{+}^{k}$, we write $t \leqslant l$ in the case that $t_{r} \leqslant l_{r}$ for all $r$.

Proposition 1. Let $l \in \mathbf{Z}_{+}^{k}$ with $|l| \geqslant 1, M_{l, s}=\left\{t \in \mathbf{Z}_{+}^{k}|1 \leqslant| t \mid \leqslant s ; t \leqslant l\right\}$, and

$$
b_{t}=\frac{(-1)^{|t|+1}|t|}{t !} \sum_{j=1}^{n}\left(\sum_{m=0}^{s-|t|} \frac{(m+|t|-1) !}{m !} p_{j}^{m}\right) \prod_{r=1}^{k} p_{j, r}^{t_{r}} \quad\left(t \in M_{l, s}\right) .
$$

Then

$$
\mathscr{P}_{s}(\{l\})=\frac{1}{|l|} \sum_{t \in M_{l, s}} \mathscr{P}_{s}(\{l-t\}) b_{t} .
$$

2. Proofs. For the proof of Theorem 1 , we need the following lemma.

Lemma 1. Let $x \in(0, \infty)$ and $j \in\{1, \ldots, n\}$. Then

$$
\begin{gathered}
\left\|V_{s}\left(-H_{j}(z)\right)\right\|=V_{s}\left(2 p_{j}\right) \\
\left\|\left[H_{j}(z)\right]^{s+1} \exp \left(x G_{1}(z)\right)\right\| \leqslant\left[\min \left\{\frac{4 c_{1}(s)}{x} \sum_{r=1}^{k} \frac{p_{j, r}^{2}}{\lambda_{r}}, 4 p_{j}^{2}\right\}\right]^{(s+1) / 2} .
\end{gathered}
$$

If $c_{4}\left(s, p_{0}\right) \beta_{1}\left(2^{-3 / 2} A^{-1}\right)<1$, then

$$
T_{1}(A):=\left\|\exp \left(A G_{1}(z)+\sum_{m=2}^{s} G_{m}(z)\right)\right\| \leqslant \frac{1}{1-c_{4}\left(s, p_{0}\right) \beta_{1}\left(2^{-3 / 2} A^{-1}\right)} .
$$

P r o o f. Let $V_{s}(y)=\sum_{i=0}^{\infty} v_{s, i} y^{i}(y \in \mathbf{C})$ as in Remark (a) after Theorem 1. Using the polynomial theorem, we obtain

$$
\begin{aligned}
V_{s}\left(-H_{j}(z)\right) & =\sum_{i=0}^{\infty} v_{s, i}\left(p_{j}-\sum_{r=1}^{k} p_{j, r} z_{r}\right)^{i}=\sum_{i=0}^{\infty} v_{s, i} \sum_{l \in \mathbf{Z}_{+}^{k}:|l| \leqslant i} \frac{i ! p_{j}^{i-|l|}}{l !(i-|l|) !} \prod_{r=1}^{k}\left(-p_{j, r} z_{r}\right)^{l_{r}} \\
& =\sum_{l \in \mathbf{Z}_{+}^{k}}\left[\sum_{i=|l|}^{\infty} \frac{v_{s, i} i ! p_{j}^{i-|l|}}{l !(i-|l|) !} \prod_{r=1}^{k} p_{j, r}^{l_{r}}\right](-z)^{l}
\end{aligned}
$$


leading to (3): $\left\|V\left(-H_{j}(z)\right)\right\|=V_{s}\left(-H_{j}((-1, \ldots,-1))\right)=V_{s}\left(2 p_{j}\right)$. Now we prove (4). For $s \in\{1,2\}$, this inequality was proved in $[14$, formulas (19) and (26)]. For even $s$, we use

$$
\left\|\left[H_{j}(z)\right]^{s+1} \exp \left(x G_{1}(z)\right)\right\| \leqslant\left\|H_{j}(z) \exp \left(\frac{x G_{1}(z)}{s+1}\right)\right\|\left\|\left[H_{j}(z)\right]^{2} \exp \left(\frac{2 x G_{1}(z)}{s+1}\right)\right\|^{s / 2}
$$

and the fact that (4) also holds for $s=0$ with $c_{1}(0)=\frac{1}{4}$ (see [14, formula (18)]). For odd $s$, the proof of (4) is similar. For the proof of (5), we may assume that $s \geqslant 2$. Using (4) and Stirling's formula, we obtain

$$
\begin{aligned}
T_{1}(A) & =\left\|\exp \left(\sum_{m=2}^{s} \sum_{j=1}^{n} \frac{(-1)^{m+1}}{m}\left[H_{j}(z)\right]^{m}\right) \exp \left(A G_{1}(z)\right)\right\| \\
& =\left\|\exp \left(A G_{1}(z)\right)+\sum_{i=1}^{\infty} \frac{1}{i !}\left(\sum_{j=1}^{n} \sum_{m=2}^{s} \frac{(-1)^{m+1}}{m}\left[H_{j}(z)\right]^{m} \exp \left(\frac{A}{i} G_{1}(z)\right)\right)^{i}\right\| \\
& \leqslant 1+\sum_{i=1}^{\infty} \frac{1}{i !}\left(\sum_{j=1}^{n} \sum_{m=2}^{s} \frac{\left\|H_{j}(z)\right\|^{m-2}}{m}\left\|\left[H_{j}(z)\right]^{2} \exp \left(\frac{A}{i} G_{1}(z)\right)\right\|\right)^{i} \\
& \leqslant 1+\sum_{i=1}^{\infty} \frac{i^{i}}{i !}\left[\frac{c_{4}\left(s, p_{0}\right)}{e} \beta_{1}\left(2^{-3 / 2} A^{-1}\right)\right]^{i} \leqslant \frac{1}{1-c_{4}\left(s, p_{0}\right) \beta_{1}\left(2^{-3 / 2} A^{-1}\right)}
\end{aligned}
$$

if $c_{4}\left(s, p_{0}\right) \beta_{1}\left(2^{-3 / 2} A^{-1}\right)<1$. The lemma is proved.

$\mathrm{P}$ r o o f of $\mathrm{T} \mathrm{h}$ e o r e $\mathrm{m}$ 1. Consider the following expansion of the difference of the generating functions of $P^{S_{n}}$ and $\mathscr{P}_{s}$ :

$$
\begin{aligned}
& \Psi_{S_{n}}(z)-\Psi_{\mathscr{P}_{s}}(z)=\left[\prod_{j=1}^{n}\left(1-\frac{\left(-H_{j}(z)\right)^{s+1}}{s+1} V_{s}\left(-H_{j}(z)\right)\right)-1\right] \Psi_{\mathscr{P}_{s}}(z) \\
& =\sum_{j=1}^{n} \sum_{\substack{1 \leqslant i(1)<\cdots<i(j) \leqslant n\\
}} \prod_{\nu=1}^{j}\left[\frac{(-1)^{s} V_{s}\left(-H_{i(\nu)}(z)\right)}{s+1}\left[H_{i(\nu)}(z)\right]^{s+1} \exp \left(\frac{B}{j} G_{1}(z)\right)\right] \\
& \quad \times \exp \left(A G_{1}(z)+\sum_{m=2}^{s} G_{m}(z)\right) .
\end{aligned}
$$

By using the polynomial theorem, we obtain $2 d_{s} \leqslant T_{1}(A) T_{2}(B)$, where $T_{1}(A)$ is defined as in Lemma 1 and

$$
\begin{aligned}
T_{2}(B):= & \sum_{j=1}^{n} \frac{1}{j !}\left[\sum_{i=1}^{n} \frac{\left\|V_{s}\left(-H_{i}(z)\right)\right\|}{s+1}\left\|\left[H_{i}(z)\right]^{s+1} \exp \left(\frac{B}{j} G_{1}(z)\right)\right\|\right]^{j} \\
\leqslant & \sum_{j=1}^{n}\left(\frac{1}{j !}\left[\frac{V_{s}\left(2 p_{0}\right)}{s+1}\left(2 p_{0}\right)^{s-1} \sum_{i=1}^{n}\left\|\left[H_{i}(z)\right]^{2} \exp \left(\frac{B}{j} G_{1}(z)\right)\right\|\right]^{j-1}\right. \\
& \left.\times \frac{V_{s}\left(2 p_{0}\right)}{s+1} \sum_{i=1}^{n}\left\|\left[H_{i}(z)\right]^{s+1} \exp \left(\frac{B}{j} G_{1}(z)\right)\right\|\right) \\
\leqslant & \frac{2 c_{2}\left(s, p_{0}\right) \beta_{s}\left(c_{1}(s) B^{-1}\right)}{\lceil s / 2-1\rceil !} \sum_{j=1}^{n} j^{s / 2-1}\left[c_{3}\left(s, p_{0}\right) p_{0}^{s-1} \beta_{1}\left(2^{-3 / 2} B^{-1}\right)\right]^{j-1} .
\end{aligned}
$$

For the latter inequality, we used (4) and Stirling's formula. In view of (5) and the relations

$$
\sum_{j=1}^{\infty} j^{\nu} x^{j-1} \leqslant \frac{d^{\nu}}{d x^{\nu}} \sum_{j=1}^{\infty} x^{j+\nu-1}=\frac{d^{\nu}}{d x^{\nu}} \sum_{j=0}^{\infty} x^{j}=\frac{\nu !}{(1-x)^{\nu+1}}
$$

for $x \in[0,1)$ and $\nu \in \mathbf{Z}_{+}$, we see that (2) is valid. The proof is completed. 
$\mathrm{Pr}$ o of of $\mathrm{Pr}$ op osition 1. Using the binomial and the polynomial theorems we obtain

$$
\begin{aligned}
& {\left[\Psi_{\mathscr{P}_{s}}(z)\right]^{-1} \sum_{l \in \mathbf{Z}_{+}^{k}}|l| \mathscr{P}_{s}(\{l\}) z^{l}=\left[\Psi_{\mathscr{P}_{s}}(z)\right]^{-1} \sum_{r=1}^{k} z_{r} \frac{\partial}{\partial z_{r}} \Psi_{\mathscr{P}_{s}}(z)} \\
& =\sum_{r=1}^{k} z_{r} \sum_{m=1}^{s} \frac{(-1)^{m+1}}{m} \sum_{j=1}^{n} \frac{\partial}{\partial z_{r}}\left(\left[H_{j}(z)\right]^{m}\right)=\sum_{j=1}^{n}\left(\sum_{r=1}^{k} p_{j, r} z_{r}\right) \sum_{m=0}^{s-1}\left(p_{j}-\sum_{r=1}^{k} p_{j, r} z_{r}\right)^{m} \\
& =-\sum_{j=1}^{n} \sum_{m=0}^{s-1} \sum_{i=0}^{m}\left(\begin{array}{c}
m \\
i
\end{array}\right) p_{j}^{m-i}\left(-\sum_{r=1}^{k} p_{j, r} z_{r}\right)^{i+1} \sum_{j=1}^{n} \sum_{i=0}^{s-1} \sum_{l \in \mathbf{Z}_{+}^{k}:|l|=i+1}^{s-1}\left(\begin{array}{c}
m \\
i
\end{array}\right) \frac{|l| !}{l !} p_{j}^{m-i}\left(\prod_{r=1}^{k}\left(-p_{j, r}\right)^{l}\right) z^{l} \\
& =-\sum_{l \in \mathbf{Z}_{+}^{k}: 1 \leqslant|l| \leqslant s}\left[\frac{(-1)^{|l|+1}|l| !}{l !} \sum_{j=1}^{n}\left(\sum_{m=|l|-1}^{s-1}\left(\begin{array}{c}
m \\
l
\end{array}\right) p_{j}^{m-|l|-1}\right) \prod_{r=1}^{k} p_{j, r}^{l_{r}}\right] z^{l} \\
& =\sum_{l \in \mathbf{Z}_{+}^{k}: 1 \leqslant|l| \leqslant s} b_{l} z^{l} .
\end{aligned}
$$

Therefore

$$
\sum_{l \in \mathbf{Z}_{+}^{k}}|l| \mathscr{P}_{s}(\{l\}) z^{l}=\Psi_{\mathscr{P}_{s}}(z) \sum_{l \in \mathbf{Z}_{+}^{k}: 1 \leqslant|l| \leqslant s} b_{l} z^{l}=\sum_{l \in \mathbf{Z}_{+}^{k}:|l| \geqslant 1} \sum_{t \in M_{l, s}} \mathscr{P}_{s}(\{l-t\}) b_{t} z^{l}
$$

Comparing the power series, the assertion is shown.

\section{REFERENCES}

1. Barbour A. D. Stein's method and Poisson process convergence. - J. Appl. Probab., 1988 , v. 25 A (Special volume), p. 175-184.

2. Barbour A. D., Xia A. Poisson perturbations. - ESAIM: Probab. Statist., 1999, v. 3, p. 131-150.

3. Чяканавичюс $B$. Аппроксимация обобщенного пуассоновско-биномиального распределения: асимпототические разложения. - Liet. Mat. Rink., 1997, v. 37, p. 117.

4. Daley D. J., Vere-Jones D. An Introduction to the Theory of Point Processes. New York: Springer-Verlag, 1988, $702 \mathrm{p}$.

5. Deheuvels P., Pfeifer D. Poisson approximations of multinomial distributions and point processes. - J. Multivariate Anal., 1988, v. 25, № 1, p. 65-89.

6. Hille E. Analytic Function Theory. V. I. - Providence, RI/New York: Amer. Math. Soc./Chelsea, 1982, 308 p.

7. Hipp C. Improved approximations for the aggregate claims distribution in the individual model. - ASTIN Bull., 1986, v. 16, p. 89-100.

8. Kerstan J. Verallgemeinerung eines Satzes von Prochorow und Le Cam. - Z. Wahrscheinlichkeitstheor. verw. Geb., 1964, v. 2, p. 173-179.

9. Kornya $P$. S. Distribution of aggregate claims in the individual risk theory model. Trans. Soc. Actuaries, 1983, v. 35, p. 823-858.

10. Круопис Ю. Точность аппроксимации обобщенного биномиального распределения свертками пуассоновских мер. -- Литов. матем. сб., 1986, т. 26, с. 53-69.

11. Пресман Э.Л. О сближении биномиальных и безгранично делимых распределений. - Теория вероятн. и ее примен., 1983 , т. 28 , в. 2, с. $372-382$.

12. Roos B. Metrische Poisson-Approximation. Ph. D. Thesis. Oldenburg: Fachbereich Mathematik, Universität Oldenburg, 1996. 
13. Roos B. Metric multivariate Poisson approximation of the generalized multinomial distribution. - Теория вероятн. и ее примен., 1998, т. 43, в. 2, с. 404-413.

14. Roos $B$. On the rate of multivariate Poisson convergence. - J. Multivariate Anal., 1999 , v. 69 , № 1, p. 120-134.

15. Witte H.-J. A unification of some approaches to Poisson approximation. - J. Appl. Probab., 1990, v. 27, № 3, p. 611-621.

\title{
MAX-SEMISTABLE LAWS IN EXTREMES OF STATIONARY RANDOM SEQUENCES ${ }^{1)}$
}

\begin{abstract}
Рассматриваются стационарные последовательности, подчиняющиеся некоторому обобщению условия Лидбеттера $D\left(u_{n}\right)$. Для таких последовательностей доказывается, что если $\left\{k_{n}\right\}$ - неубывающая последовательность целых чисел и $\lim _{n \rightarrow+\infty} k_{n+1} / k_{n}=r \geqslant 1$, то предельным законом для максимума первых $k_{n}$ величин является тах-полуустойчивый закон. Это утверждение обобщает соответствующий результат для последовательностей независимых одинаково распределенных случайных величин [3] и теорему Лидбеттера об экстремальных типах [4]. Мы доказываем также, что предельное поведение этого максимума можно вывести из предельного поведения соответствующего максимума ассоциированной независимой последовательности, и обобшаем хорошо известное понятие экстремального индекса.
\end{abstract}

Ключевые слова и фразы: максимум, слабая сходимость, стационарность, max-полуустойчивые законы.

1. Introduction. Max-semistable laws arise in the theory of extremes as limit in distribution of the maximum, suitably normalized, of $k_{n}$ independent and identically distributed (i.i.d.) random variables, where $\left\{k_{n}\right\}$ is a nondecreasing integer sequence satisfying

$$
\lim _{n \rightarrow+\infty} \frac{k_{n+1}}{k_{n}}=r, \quad r \in[1,+\infty[\text {. }
$$

Following [2] we will say that a distribution function (d.f.) $G$ on $\mathbf{R}$ is $\ell$-max-semistable if there are reals $r>1, \gamma>0$ and $\beta$ such that

$$
G(x)=G^{r}\left(\frac{x}{\gamma}+\beta\right), \quad x \in \mathbf{R},
$$

or equivalently, if there are a sequence of i.i.d. random variables with d.f. $F$ and two real sequences $\left\{a_{n}>0\right\}$ and $\left\{b_{n}\right\}$ for which

$$
\lim _{n \rightarrow+\infty} F^{k_{n}}\left(\frac{x}{a_{n}}+b_{n}\right)=G(x)
$$

for each continuity point of $G$, with $\left\{k_{n}\right\}$ satisfying (1) - where $\ell$ stands for linear normalization. The general definition of max-semistable law is given in [7].

* Departamento de Matemática, Universidade de Coimbra, Portugal; e-mail: mgtm@mat.uc.pt

** D.E.I.O., Universidade de Lisboa, Portugal.

1) Partially supported by JNICT/PRAXIS XXI/FEDER. 